\title{
Bodily self and immune self: is there a link?
}

\author{
Marcello Costantini ${ }^{1,2,3 *}$ \\ ${ }^{1}$ Laboratory of Neuropsychology and Cognitive Neuroscience, Department of Neuroscience and Imaging, University G. d'Annunzio, Chieti, Italy \\ 2 Institute for Advanced Biomedical Technologies, University G. d'Annunzio, Chieti, Italy \\ ${ }^{3}$ Mind, Brain Imaging and Neuroethics, Institute of Mental Health Research, University of Ottawa, Ottawa, ON, Canada \\ *Correspondence: marcello.costantini@unich.it
}

Edited by:

Silvio Ionta, Swiss Federal Institute of Technology Zurich, Switzerland

Reviewed by:

Bigna Lenggenhager, University Hospital Zurich, Switzerland

Keywords: bodily self-consciousness, multisensory integration, immune system, immunity, sense of ownership

Normally we experience the physical body as our own, except in rare conditions and transitory illusions. Cognitive neuroscientists, philosophers, and psychologists call this feeling bodily self-consciousness (Damasio, 2003; Gallagher, 2005; Legrand, 2006; Blanke and Metzinger, 2009; Ferri et al., 2011, 2012). The Rubber Hand Illusion is though to operationalize on bodily self-consciousness (David et al., 2013, for a different view). By using this illusion it has been demostrated that bodily self-consciousness is highly variable across healthy individuals (Haans et al., 2012). This means that the susceptibility to the illusion largely varies across individuals. The origin of such variability remains largely unknown. In this opinion paper, I propose the possibility that it can be traced, in part, to the individual's immune system ability to differentiate the self from nonself. In particular, I suggest a biological substrate for such dependency.

The intriguing idea of a link between the Bodily Self and the Immune Self was proposed by Antonio Damasio more than 10 years ago (Damasio, 2003). Here the Bodily Self is defined as a nonpropositional representation of interoexteroceptive information (Haggard et al., 2003; Pacherie, 2008); and the Immune Self is defined as whatever the immune system recognize as belonging to the hosting body (Nossal, 2001). Damasio's fascinating suggestion remains largely at the theoretical level, with little empirical support. However, recently things are changing. Barnsley and colleagues found that during the Rubber Hand Illusion the immune system treats the concealed hand as a foreign body part, as demonstrated by increases histamine reactivity (Barnsley et al., 2011).
Thus, Barnsley et al's data suggest a biological link between bodily self-consciousness and the immune system.

The immune system is a set of molecules, proteins and processes that protects against disease. To do that, the immune system must be able to distinguish the host's own cells from virus and bacteria. In principle the immune system has the potentiality to destroy the host (i.e., the Self) and the pathogens (i.e., the nonself). When the immune system appropriately regulates by engaging in biodestructive activity of a pathogen, then that pathogen is considered as part of the "nonself," while tolerance towards the healthy tissue of the host is considered part of the "self." However, when biodestructive activity is inappropriately regulated, autoimmunity might occur. Autoimmunity is indeed the error of the immune system in recognizing its own cells as nonself. Prominent examples include Celiac disease, diabetes mellitus type 1, systemic lupus erythematosus, Hashimoto's thyroiditis, Graves' disease, rheumatoid arthritis, and multiple sclerosis. The presence of an autoimmune disease is signaled by the appearance of autoantibodies in the patient blood. Among immunologists, different mechanisms have been proposed to explain the ability of the immune system to differentiate pathogens from the host, including altered self (Houghton, 1994), danger theory (Matzinger, 2002) and discontinuity theory (Pradeu et al., 2013). However, a detailed review of such proposals is far from the aim of the present paper.

How it is possible to explain an empirical link between the Bodily Self and the
Immune Self? One possibility is to look at the basic mechanisms driving the Bodily Self and to look whether such mechanisms are sensitive to the status of the immune system.

According to some authors, the foundation of the self lies in the brain networks representing the body (Damasio, 2003; Gallagher, 2005; Blanke and Metzinger, 2009) and integrating interoceptive and exteroceptive inputs (Tsakiris et al., 2011). In the case of the rubber hand illusion, multisensory integration between vision and touch "changes the phenomenal status of the rubber hand from inanimate object to part of one's own body" (Ehrsson, 2012). Since multisensory bodily inputs are continuous, whereas external objects of perception are transient and therefore not continuous, these multisensory bodily inputs have been proposed as the basis for the Bodily Self (Arzy et al., 2006; Aspell et al., 2009; Ionta et al., 2011a,b, 2014; Limanowski and Blankenburg, 2013). According to this view, when multisensory bodily signals (i.e., visual and spatio-temporal signals) received from a body part match, a sense of ownership then arises for that body part (Ehrsson, 2012). Such constitutive role of multisensory integration in bodily self-consciousness might bridge the gap between the Bodily Self and the Immune Self. Indeed, despite its crucial role, multisensory integration is not an innate ability. Neurons with multisensory capability in the superior colliculus (SC) are ineffective in combining cross-modal stimuli at early stages of life (Wallace and Stein, 1997, 2001, 2007). They require postnatal maturation to acquire this capability. 
Supporting this view is the finding that manipulating the spatio-temporal features of cross-modal stimuli has a strong impact on the normal development of multisensory neurons (Wallace et al., 2004). That is, changing the natural statistics of the environment (Chandrasekaran et al., 2009), changes the way neurons encode future stimuli (Wallace and Stein, 2007). This data support the idea that axon pruning and neural plasticity are necessary conditions for the maturation of multisensory neurons.

Strikingly, neural plasticity in the SC and other brain structures is deeply intertwined with the immune system via substances called cytokines, with the interleukins being prominent examples (Boulanger, 2009; Yirmiya and Goshen, 2011). These cells are used by the immune system to orchestrate the production of antibody and memory cell formation. The name interleukins mirrors their role in communication between leukocytes.

Interestingly, the prolonged exposure to pro-inflammatory cytokines causes premature stabilization of developing synapses within the tectum (i.e., the SC in mammals). Therefore, this prevents normal synaptic refinement and elimination that occurs during development. Indeed, during development, the optic tectum undergoes a substantial amount of modification, both locally (e.g., within the tectum itself) and in its projection to the retina (Lee et al., 2010). A considerable amount of this modification involves consolidation and stabilization of some synapses, and weakening and elimination of others. This evidence is in line with the protracted period of postnatal maturation required by multisensory neurons to develop the ability of combining crossmodal stimuli (Stein et al., 1973; Wallace and Stein, 1997, 2001). Other evidence of the link between neural plasticity and immune molecules comes from studies on long-term potentiation (LTP). In 1998, Schneider et al. demonstrated that the pro-inflammatory cytokine IL-1 in the hippocampus plays a pivotal role in long term potentiation as well as in maintaining it. The dose-dependent effect of IL-1 on memory and LTP is also demonstrated by the detrimental effect of intracerebroventricular administration of IL-1 on the acquisition of spatial memories after spatial water maze training (Oitzl et al., 1993). In the same vein, chronic exposure to IL-1 produces important deficit in spatial memory, as measured by means of the water maze paradigm, as well as diminished long-term contextual fear memory (Moore et al., 2009; Hein et al., 2010). Other cytokines, genes, and proteins play a role in the communication between the brain and the immune system (Boulanger and Shatz, 2004; Boulanger, 2009). For instance, several studies showed a negative effect of elevated IL-6 levels on synaptic plasticity (Li et al., 1997).

In summary, a basic sense of Self in housed in the brain structures representing the body (Legrand, 2006; Blanke, 2012). Such representations depend upon multisensory bodily signals. To develop the ability to integrate bodily signals axon pruning, neurogenesis and synaptic plasticity are mandatory processes (Stein et al., 1973). These processes, in turn, are deeply intertwined with the immune system (Boulanger, 2009; Yirmiya and Goshen, 2011). From this perspective, the Bodily Self and the Immune Self have a common biological background. I am not proposing a new theory of the Self, but I am proposing an extension to the theoretical framework that is being developed to better understand the Self. The immune system consists of many proteins, molecules and processes. Hence, my proposal is speculative and not exhaustive. Future empiric studies should be conducted to test this proposal.

\section{ACKNOWLEDGMENTS}

This work is supported by a grant from BIAL foundation and by a grant from Volkswagen foundation. I thank Jeffrey Robinson for the English revision of the text.

\section{REFERENCES}

Arzy, S., Thut, G., Mohr, C., Michel, C. M., and Blanke, O. (2006). Neural basis of embodiment: distinct contributions of temporoparietal junction and extrastriate body area. J. Neurosci. 26, 8074-8081. doi: 10.1523/JNEUROSCI.074506.2006

Aspell, J. E., Lenggenhager, B., and Blanke, O. (2009). Keeping in touch with one's self: multisensory mechanisms of self-consciousness. PLoS ONE 4:e6488. doi: 10.1371/journal.pone.0006488

Barnsley, N., Mcauley, J. H., Mohan, R., Dey, A., Thomas, P., and Moseley, G. L. (2011). The rubber hand illusion increases histamine reactivity in the real arm. Curr. Biol. 21, R945-R946. doi: 10.1016/j.cub.2011.10.039

Blanke, O. (2012). Multisensory brain mechanisms of bodily self-consciousness. Nat. Rev. Neurosci. 13, 556-571. doi: 10.1038/nrn3292nrn3292

Blanke, O., and Metzinger, T. (2009). Full-body illusions and minimal phenomenal selfhood. Trends Cogn. Sci. 13, 7-13. doi: 10.1016/j.tics.2008.10.003 S1364-6613(08)00250-7

Boulanger, L. M. (2009). Immune proteins in brain development and synaptic plasticity. Neuron 64, 93-109. doi: 10.1016/j.neuron.2009.09.001

Boulanger, L. M., and Shatz, C. J. (2004). Immune signalling in neural development, synaptic plasticity and disease. Nat. Rev. Neurosci. 5, 521-531. doi: $10.1038 / \mathrm{nrn} 1428$

Chandrasekaran, C., Trubanova, A., Stillittano, S., Caplier, A., and Ghazanfar, A. A. (2009). The natural statistics of audiovisual speech. PLoS Comput. Biol. 5:e1000436. doi: 10.1371/journal.pcbi. 1000436

Damasio, A. (2003). Mental self: the person within. Nature 423:227. doi: 10.1038/423227a

David, N., Fiori, F., and Aglioti, S. M. (2013). Susceptibility to the rubber hand illusion does not tell the whole body-awareness story. Cogn. Affect. Behav. Neurosci. doi: 10.3758/s13415-013-0190-6. [Epub ahead of print].

Ehrsson, H. H. (2012). The Concept of Body Ownership and its Relation to Multisensory Integration. Cambridge, MA: MIT Press.

Ferri, F., Frassinetti, F., Ardizzi, M., Costantini, M., and Gallese, V. (2012). A sensorimotor network for the bodily self. J. Cogn. Neurosci. 24, 1584-1595. doi: 10.1162/jocn_a_00230

Ferri, F., Frassinetti, F., Costantini, M., and Gallese, V. (2011). Motor simulation and the bodily self. PLoS ONE 6:e17927. doi: 10.1371/journal.pone.0017927

Gallagher, S. (2005). How the Body Shapes the Mind. Oxford: Oxford University Press. doi: 10.1093/ 0199271941.001.0001

Haans, A., Kaiser, F. G., Bouwhuis, D. G., and Ijsselsteijn, W. A. (2012). Individual differences in the rubber-hand illusion: predicting self-reports of people's personal experiences. Acta Psychol. (Amst). 141, 169-177. doi: 10.1016/j.actpsy.2012. 07.016

Haggard, P., Taylor-Clarke, M., and Kennett, S. (2003). Tactile perception, cortical representation and the bodily self. Curr. Biol. 13, R170-R173. doi:10.1016/ S0960-9822(03)00115-5

Hein, A. M., Stasko, M. R., Matousek, S. B., ScottMckean, J. J., Maier, S. F., Olschowka, J. A., et al. (2010). Sustained hippocampal IL-1 $\beta$ overexpression impairs contextual and spatial memory in transgenic mice. Brain Behav. Immun. 24, 243-253. doi: 10.1016/j.bbi.2009.10.002

Houghton, A. N. (1994). Cancer antigens: immune recognition of self and altered self. J. Exp. Med. 180, 1-4. doi: 10.1084/jem.180.1.1

Ionta, S., Gassert, R., and Blanke, O. (2011a). Multisensory and sensorimotor foundation of bodily self-consciousness - an interdisciplinary approach. Front. Psychol. 2:383. doi: 10.3389/fpsyg.2011. 00383

Ionta, S., Heydrich, L., Lenggenhager, B., Mouthon, M., Fornari, E., Chapuis, D., et al. (2011b). Multisensory mechanisms in temporo-parietal cortex support self-location and first-person 
perspective. Neuron 70, 363-374. doi: 10.1016/j. neuron.2011.03.009

Ionta, S., Martuzzi, R., Salomon, R., and Blanke, O. (2014). The Brain Network reflecting Bodily Selfconsciousness: a functional connectivity study. Soc. Cogn. Affect. Neurosci. doi: 10.1093/scan/nst185. [Epub ahead of print].

Lee, R. H., Mills, E. A., Schwartz, N., Bell, M. R., Deeg, K. E., Ruthazer, E. S., et al. (2010). Neurodevelopmental effects of chronic exposure to elevated levels of pro-inflammatory cytokines in a developing visual system. Neural Dev. 5:2. doi: 10.1186/1749-8104-5-2

Legrand, D. (2006). The bodily self: The sensorimotor roots of pre-reflective self-consciousness. Phenomenol. Cogn. Sci. 5, 89-118. doi: 10.1007/ s11097-005-9015-6

Li, A. J., Katafuchi, T., Oda, S., Hori, T., and Oomura, Y. (1997). Interleukin-6 inhibits long-term potentiation in rat hippocampus slices. Brain Res. 748, 30-38. doi: 10.1016/S0006-8993(96)01283-8

Limanowski, J., and Blankenburg, F. (2013). Minimal self-models and the free energy principle. Front. Hum. Neurosci. 7:547. doi: 10.3389/fnhum.2013. 00547

Matzinger, P. (2002). The danger model: a renewed sense of self. Science 296, 301-305. doi: 10.1126/ science. 1071059

Moore, A. H., Wu, M., Shaftel, S. S., Graham, K. A., and O'banion, M. K. (2009). Sustained expression of interleukin- $1 \beta$ in mouse hippocampus impairs spatial memory. Neuroscience 164, 1484-1495. doi: 10.1016/j.neuroscience.2009.08.073
Nossal, G. J. (2001). A purgative mastery. Nature 412, 685-686. doi: 10.1038/35089152

Oitzl, M., Van Oers, H., Schobitz, B., and De Kloet, E. R. (1993). Interleukin-1 $\beta$, but not interleukin6, impairs spatial navigation learning. Brain Res. 613, 160-163. doi: 10.1016/0006-8993(93) 90468-3

Pacherie, E. (2008). The phenomenology of action: a conceptual framework. Cognition 107, 179-217. doi: 10.1016/j.cognition.2007.09.003

Pradeu, T., Jaeger, S., and Vivier, E. (2013). The speed of change: towards a discontinuity theory of immunity? Nat. Rev. Immunol. 13, 764-769. doi: 10.1038/nri3521

Schneider, H., Pitossi, F., Balschun, D., Wagner, A., Del Rey, A., and Besedovsky, H. O. (1998). A neuromodulatory role of interleukin- $1 \beta$ in the hippocampus. Proc. Natl. Acad. Sci. U.S.A. 95, 7778-7783. doi: 10.1073/pnas.95.13.7778

Stein, B. E., Labos, E., and Kruger, L. (1973). Sequence of changes in properties of neurons of superior colliculus of the kitten during maturation. J. Neurophysiol. 36, 667-679.

Tsakiris, M., Tajadura-Jiménez, A., and Costantini, M. (2011). Just a heartbeat away from one's body: interoceptive sensitivity predicts malleability of body-representations. Proc. R. Soc. B Biol. Sci. 278, 2470-2476. doi: 10.1098/rspb.2010.2547

Wallace, M. T., Perrault, T. J. Jr., Hairston, W. D., and Stein, B. E. (2004). Visual experience is necessary for the development of multisensory integration. J. Neurosci. 24, 9580-9584. doi: 10.1523/ JNEUROSCI.2535-04.2004
Wallace, M. T., and Stein, B. E. (1997). Development of multisensory neurons and multisensory integration in cat superior colliculus. J. Neurosci. 17, 2429-2444.

Wallace, M. T., and Stein, B. E. (2001). Sensory and multisensory responses in the newborn monkey superior colliculus. J. Neurosci. 21, 8886-8894.

Wallace, M. T., and Stein, B. E. (2007). Early experience determines how the senses will interact J. Neurophysiol. 97, 921-926. doi: 10.1152/jn. 00497.2006

Yirmiya, R., and Goshen, I. (2011). Immune modulation of learning, memory, neural plasticity and neurogenesis. Brain Behav. Immun. 25, 181-213. doi: 10.1016/j.bbi.2010.10.015

Received: 23 January 2014; accepted: 24 February 2014; published online: 18 March 2014.

Citation: Costantini M (2014) Bodily self and immune self: is there a link? Front. Hum. Neurosci. 8:138. doi: 10.3389/fnhum.2014.00138

This article was submitted to the journal Frontiers in Human Neuroscience.

Copyright (c) 2014 Costantini. This is an open-access article distributed under the terms of the Creative Commons Attribution License (CC BY). The use, distribution or reproduction in other forums is permitted, provided the original author(s) or licensor are credited and that the original publication in this journal is cited, in accordance with accepted academic practice. No use, distribution or reproduction is permitted which does not comply with these terms. 